\title{
Produtos à base de Kefir desenvolvidos e estudados no Brasil
}

\author{
Kefir-based products developed and studied in Brazil \\ Productos a base de Kefir desarrollados y estudiados en Brasil
}

Recebido: 25/05/2021 | Revisado: 01/06/2021 | Aceito: 02/06/2021 | Publicado: 18/06/2021

\author{
Marina de Souza Brasil da Silva \\ ORCID: https://orcid.org/0000-0002-5587-7526 \\ Universidade Federal do Triângulo Mineiro, Brasil \\ E-mail: marina.brasil605@gmail.com \\ Mônica Hitomi Okura \\ ORCID: http://orcid.org/0000-0002-9875-9378 \\ Universidade Federal do Triângulo Mineiro, Brasil \\ E-mail: monica.okura@uftm.edu.br
}

\begin{abstract}
Resumo
O Kefir é um alimento probiótico que apresenta grande potencial de aplicação e desenvolvimento de novos produtos, por ser uma matéria prima de fácil preparo e baixo custo. Além disso, seu consumo apresenta diversos benefícios associados à saúde. O mercado alimentício tenta atender a demanda crescente da busca por alimentos mais nutritivos. Essa nova tendência reforça o incentivo ao desenvolvimento de alimentos funcionais. Por isso, o presente trabalho levantou bibliografias sobre o desenvolvimento e a aceitação de produtos à base de Kefir em diferentes estados brasileiros. Observou-se um aumento significativo de trabalhos científicos relacionados ao tema nos últimos anos, principalmente artigos sobre saborização do fermentado de Kefir com o intuito de aumentar sua aceitação sensorial, essa subclasse ocupou $45,71 \%$ dos artigos analisados e dos produtos em que foram avaliados sensorialmente, $97,14 \%$ deles apresentaram boa aceitação sensorial. Minas Gerais foi o estado que mais se destacou em número de publicações relacionadas ao desenvolvimento de novos produtos à base de Kefir, com 17,14\%. Portanto, apesar do Kefir ser um produto pouco consumido no Brasil, os estudos demonstram uma alta aceitação sensorial, o que incentiva o desenvolvimento de novos produtos à base dele.
\end{abstract}

Palavras-chave: Probiótico; Aceitação; Alimento funcional; Nutrecêutico; Fermentados.

\begin{abstract}
Kefir is probiotic food that presents great potential for application and development of new products, because it is a raw material of easy preparation and low cost. In addition, its consumptions has several health-related benefits. The food market tries to meet the growing demand of the search for more nutritious foods. This new trend reinforces the incentive to develop functional foods. Therefore, the present work raised bibliographies on the development and acceptance of Kefir-based products in different Brazilian states. In recent years there was a significant increase in scientific papers related to the topic, mainly articles on flavoring kefir fermented in order to increase its sensory acceptance. This subclass occupied $45.71 \%$ of the articles analyzed and $97,14 \%$ of the products in which they were sensory evaluated presented good sensory acceptance. Minas Gerais was the state that stood out the most in the number of publications related to the development of new Kefir-based products, with $17.14 \%$ of publications. Therefore, despite Kefir being a little consumed product in Brazil, studies show a high sensory acceptance which encourages the development of new products based on it.
\end{abstract}

Keyword: Probiotic; Acceptance; Functional food; Nutraceutical; Fermented.

\section{Resumen}

El Kéfir es un alimento probiótico que tiene gran potencial de aplicación y desarrollo de nuevos productos, por ser una matéria prima de fácil preparación e bajo costo. Además, tu consumes tiene vários beneficios relacionados con la salud. El mercado de los alimentos trata de comprender la creciente demanda de búsqueda por comidas más nutritiva. Esta nueva tendencia refuerza el incentivo a la producción de alimentos funcionales. Por eso, esto trabajo buscó bibliografias de desarrollo y aceptación de productos de Kéfir em diferentes estados brasileños. Se observó un aumento significativo de trabajos científicos relacionados con el tema en los últimos años, principalmente artículos sobre sazonar el fermentado de kéfir, con el propósito de aumentar tu aceptación sensorial, esta subclase ocupó $45,71 \%$ de los artículos analizados y de los productos que fueron evaluados sensorialmente, $97,14 \%$ de ellos mostraron buena aceptación sensorial. Minas Gerais fue el estado que más se destacó en número de publicaciones relacionadas con el desarollo de nuevos productos de Kéfir, con 17,14\%. Por consiguiente, a pesar de lo Kéfir ser un producto poco consumido aquí en Brasil, los estudios demuestran una alta aceptación sensorial, que fomenta el desarrollo de nuevos produtos basados en él.

Palabras clave: Probiótico; Aceptación; Alimento funcionale; Nutrecêutico; Fermentados. 


\section{Introdução}

Atualmente, cresce o número de pessoas preocupadas em adotar hábitos alimentares mais saudáveis, isso se deve principalmente ao crescente número de doenças crônicas transmissíveis que acometem a população (Dias et al., 2020).

O Kefir é uma bebida produzida através da fermentação de leites, sucos de fruta ou água adoçada (Oliveira, 2016). É um alimento funcional e pode ser classificado como probiótico (Moura et al., 2020) uma vez que quando ministrados de forma adequada conferem benefícios à saúde do consumidor (Gomes et al., 2020), isso porque, segundo Oliveira (2016) seus grãos são constituídos por lactobacilos, leveduras e fungos filamentosos.

Por ser um probiótico, o Kefir apresenta diversos benefícios a saúde se consumidos com regularidade, como ação de atividade antimicrobiana, antitumoral, desintoxicante, proteção a células tronco contra a apoptose, auxilia no equilíbrio da microbiota intestinal, estimula defesas naturais (Oliveira, 2016). Além disso, o Kefir pode ser consumido por pessoas com intolerância à lactose (Gomes et al., 2020).

Por esses motivos, o presente trabalho tem como objetivo analisar a aceitação e o desenvolvimento de novos produtos à base de Kefir no Brasil em diferentes trabalhos com o intuito de ampliar o conhecimento sobre o tema, expandindo seu consumo.

\section{Procedimentos Metodológicos}

A metodologia deste estudo foi caracterizada como um estudo exploratório de natureza quantitativa. Com a pesquisa exploratória foi possível fazer o levantamento bibliográfico e analisar exemplos que estimulam a compreensão e que mantem foco no tema, onde foram feitas pesquisas bibliográficas e citações.

Foi realizado um mapeamento da produção científica na base Google acadêmico, pubmed e scielo utilizando a palavra-chave "kefir" no título do artigo, sendo que foram analisados artigos científicos de 1916 a 2021 . Após filtrar os dados foram encontradas trinta e cinco (35) produções científicas sobre o tema relacionado na pesquisa.

\section{Resultados e Discussão}

a) Alimento Funcional

Com a modernização da sociedade observou-se mudanças nos seus padrões de vida. Nota-se hoje um aumento de casos de pessoas com sintomas depressivos, de estresse ou cansaço o que levou a observar que em alguns locais onde se havia uma alimentação muito específica, havia uma baixa incidência de algumas doenças, como o caso dos esquimós com baixo índice de problemas cardíacos devido a rotina alimentar rica em ômega 3 e 6, provenientes dos peixes e também dos franceses devido a rotina alimentar rica em compostos fenólicos provenientes do vinho tinto (Moraes, 2006).

Com o aumento da expectativa de vida e aumento de algumas enfermidades, os consumidores estão cada vez mais interessados em buscar alimentos mais saudáveis que possam agir de forma a prevenir algumas doenças. Esse segmento alimentício vem crescendo de forma exorbitante, um mercado hoje estimado entre seis e sessenta bilhões de dólares (Arabbi, 2001).

Observou-se que com o passar dos anos, houve um aumento do número de pesquisas direcionadas a relação entre a dieta e o aparecimento de doenças crônicas. Isso porque, a baixa incidência de algumas doenças em determinadas populações despertou curiosidade aos cientistas para tentar determinar essa relação (Arabbi, 2001).

Segundo Vidal et al. (2012), todos os alimentos que apresentam capacidade de nutrir são considerados funcionais, entretanto, após a primeira definição de alimento funcional proposta no Japão, mudou-se a visão sobre o alimento funcional, passando a precisar proporcionar algum efeito positivo fisiológico ou metabólico, devido há algum nutriente presente promovendo a manutenção das funções do organismo. 
Os alimentos funcionais devem além de nutrir, apresentar propriedades benéficas a quem consome com regularidade, comprovando o benefício a pelo menos uma função alvo do organismo, devido a ingredientes fisiologicamente saudáveis. Ou seja, esses alimentos evidenciam a capacidade de regular certas funções corporais a fim de auxiliar no combate e ou prevenção de algumas doenças (Moraes, 2006).

Os alimentos funcionais eles não curam doenças e nem devem ser consumidos como medicamentos esses alimentos podem prevenir o aparecimento de doenças e ajudar a combate-las se fizerem parte de uma dieta regular, auxiliando o fortalecimento do organismo e de seu sistema imunológico (Vidal et al., 2012).

Moraes (2006), comentam que se pode classificar os alimentos e ou ingredientes funcionais de duas formas: a primeira relaciona-se a sua fonte alimentar, ou seja, de origem animal ou vegetal, a segunda se relaciona aos benefícios que estes provem a saúde, ou seja, na área em que ocorre esse benefício, no sistema cardiovascular, gastrointestinal, no crescimento, desenvolvimento e diferenciação celular, dentre outros.

Foi somente na década de 80, no Japão, que foi introduzido pela primeira vez o termo "alimentos funcionais", porém com outra nomenclatura. Na época, se referia a alimentos processados que continham ingredientes funcionais, ou seja, que auxiliavam em algumas funções específicas do corpo além da função de nutrir. Esses alimentos foram definidos como “Alimentos para uso específico de saúde”, de acordo com a definição japonesa, são alimentos que devido a sua constituição química, apresentam ingredientes funcionais que agem de forma benéfica a saúde e não devem expor o consumidor ao risco de saúde (Moraes, 2006).

Após o surgimento do conceito de alimentos funcionais, diversos países adotaram esse conceito e começaram a criar suas definições. Em alguns países como Japão, Estados Unidas e Europa, muitos alimentos funcionais vêm sendo comercializados de forma industrializada. No Brasil, a produção em escala industrializada ainda é muito pequena, mais dados indicam que o país pode se tornar um grande produtor de alimentos funcionais in natura e processados no futuro (Vidal et al., 2012).

\section{b) Alimento nutracêutico}

O termo nutracêutico foi criado por De Felice em 1989, com o intuito de diferenciar alimentos funcionais de um medicamento. Definiu-se nutracêutico como um alimento ou parte dele que oferece benefícios à saúde, incluindo prevenção e tratamento de doenças (Arabbi, 2001; Moraes, 2006).

Sua ação engloba desde o suprimento da necessidade diária de vitaminas e minerais até a promoção de prevenção contra doenças infecciosas. A palavra nutracêutico pode se relacionar tanto com nutrientes isolados industrialmente, alimentos geneticamente modificados, suplementos dietéticos, produtos herbais e alguns produtos processados como cereais e bebidas (Moraes, 2006).

Segundo Arabbi (2001), o Food and Drug Administration (FDA) propôs uma nova categoria para enquadrar os compostos nutracêuticos separada do regulamento para alimentos e medicamentos. Isso se deve, pois os nutracêuticos podem ser alimentos funcionais e também suplementos dietéticos sob o olhar da indústria farmacêutica. Os compostos nutracêuticos podem ser nutrientes naturais encontrado em forma de tablete e em pó, não necessariamente em um alimento completo ou medicamento.

\section{c) Probióticos}

O termo probiótico tem origem grega, sua tradução literária significa "pró-vida". Ao longo dos anos, diferentes percepções foram construídas em cima do termo probiótico, alguns cientistas relacionavam o termo a produção de secreção de um protozoário para estimular o crescimento de outros microrganismos, outros para determinar suplementos alimentares de 
animais. Porém foi somente Fuller que definiu probiótico como sendo suplementos alimentares que contêm bactérias vivas que auxiliam beneficamente no intestino (Coppola \& Gil-Turnes, 2004).

Moraes (2006), comentam que probióticos são microrganismos vivos que podem ser adicionados na dieta como suplementos, modificando de forma benéfica a saúde da flora intestinal. O termo probiótico pode ser também conhecido como bioterapêuticos, bioprotetores e bioprofiláticos. A definição mais conhecida é de que são microrganismos vivos que administrados em quantidades adequadas, podem conferir benefícios a saúde da flora do consumidor.

Os probióticos são definidos como suplementos alimentares contendo bifidobactérias, que agem de forma a beneficiar a colonização intestinal (Arabbi, 2001). De acordo com Coppola \& Gil- Turnes (2004), os compostos probióticos são frequentemente usados para a prevenção e tratamento de doenças, como em distúrbios gastrointestinais, regulação intestinal e também na inibição carcinogênica.

\section{d) Leite fermentado}

De acordo com dados históricos, acredita-se que o leite fermentado foi produzido pela primeira vez por nômades que estocavam seus leites em recipientes feitos com estômagos de bodes. Essa produção ocorreu de forma acidental devido ao favorecimento de proliferação bacteriana, sendo responsáveis por causar modificações físico químicas na matéria prima. Até hoje, países situados na região da Eurásia possuem o costume de elaborar leites fermentados e outros derivados lácteos (Costa et al., 2013). Além de ser um método de conservação, a fermentação possibilita o aumento do valor nutricional do alimento (Silva et al., 2020b).

O leite fermentado apresenta alto valor agregado, principalmente quando o assunto é o desenvolvimento de novos produtos. Isso acontece, porque o leite fermentado é probiótico agindo de forma benéfica a saúde (Costa et al., 2013), onde os microrganismos causam efeitos bioquímicos sobre os nutrientes da matéria prima e ações benéficas a fisiologia do consumidor (Sales, 2017), sendo muito explorado industrialmente (Costa et al., 2013).

\section{e) Kefir}

O Kefir é uma bebida láctea fermentada probiótica, oriunda das montanhas caucasianas europeias (Gomes et al., 2020). Esse pode possuir outros nomes como tibicos, cogumelos tibetanos, quefir, plantas e cogumelos de iogurte, kefer, kepi, kephir, kiaphur, kippi, variando com a região de produção (Silva et al., 2020b).

Kefir deriva de Keif, palavra de origem turca que significa em tradução livre como "bom sentimento" ou "sentir-se bem". Foi apenas no século 20 que Kefir foi introduzido no restante do mundo (Oliveira, 2016).

De acordo com a Instrução Normativa no 46 de 2007 do Ministério da Agricultura, Pecuária e Abastecimento (MAPA), define-se Kefir como produto de fermentação ácido-lática cujo produtos são ácido lático, etanol e dióxido de carbono. Seus grânulos são constituídos por leveduras fermentadores e não fermentadoras de lactose, Lactobacillus, Bifidobacterium, Streptococcus e Thermophilus (BRASIL, 2007).

Os grânulos apresentam formatos irregulares, entre 1 a $6 \mathrm{~mm}$, de coloração branca e aspecto gelatinoso. Devido a um composto formado por glicose e galactose, denominado Kefirano. O Kefir apresenta características que possibilitam o aumento da viscosidade devido a interações com os componentes constituintes do leite (Araújo et al., 2020).

De acordo com Gomes et al. (2020), os grânulos de Kefir podem ser definidos como uma agregação de leveduras e bactérias ácido láticas e acéticas que se multiplicam em simbiose e são envoltas na matriz de Kefiran.

O Kefir ainda não é compreendido completamente, devido à complexidade celular de seus grãos (Oliveira, 2016) e sua composição pode variar de acordo com a origem dos grânulos (Santos, 2012). Embora a composição microbiológica dos grãos 
de Kefir se divergirem, os gêneros bacterianos mais presentes são Lactobacillus, Acinetobacter, Enterobacter e Pseudomonas, enquanto das leveduras são Candida, Saccharomyces, Dipodascaceae e Aspergillus (Gomes et al., 2020)

De acordo com Alves (2020), estudos conseguiram isolar e identificar 359 espécies de bactérias e leveduras dos grânulos de Kefir de origem brasileira, sendo predominantemente encontrados bactérias láticas, seguidas por leveduras e bactérias ácido acéticas.

Inúmeras bactérias contidas nos grãos de Kefir apresentam propriedade probiótica, além disso, ainda apresenta a possibilidade de agregar outros microrganismos a sua composição, por isso o Kefir passou a ser considerado um probiótico completo (Dias et al., 2020).

O complexo microbiológico contido nos grãos ao se multiplicarem levam a produção de ácido lático, compostos aromatizantes (Silva et al., 2020b) e substâncias bioativas, responsáveis por propriedades nutracêuticas (Oliveira et al., 2021). Diferentemente de outros produtos lácteos fermentados, os grânulos de Kefir aumentam sua biomassa ao longo do processo fermentativo, o que permite a recuperação dos grãos pós fermentação. No Brasil, o leite fermentado de Kefir é produzido de forma artesanal, por isso, culturalmente os grânulos de Kefir não são vendidos e sim doados (Oliveira et al., 2021).

Além disso, o Kefir pode ser utilizado como cultura iniciadora de outros produtos fermentados o que pode conferir maior qualidade, estabilidade e também segurança microbiológica ao alimento (Oliveira et al., 2021).

De acordo com a literatura, já foram encontrados inúmeros benefícios do consumo regular de Kefir (Silva et al., 2020b), esses benefícios estão associados aos microrganismos possuírem função probiótica, as atividades dos exopolissacarídeos e aos peptídeos gerados durante o processo de fermentação (Dias et al., 2020). Dentre os benefícios pode se citar a dietoterapia, oncologia comparada, nutrição humana (Silva et al., 2020b), melhora na atividade intestinal, além de ser uma opção de consumo para intolerantes a lactose (Gomes et al., 2020), redução do colesterol e propriedade antitumorais, controle de glicose plasmática, atividade antioxidante, anticancerígena, antialérgica e anti-inflamatória (Dias et al. 2020), aumento da velocidade de cicatrização, inibição da enzima conversora de angiotensina e melhora na resposta do sistema imune (Gonçalves et al., 2018).

O leite fermentado de Kefir pode ser produzido através de vários substratos, água, todos os tipos de leite de origem animal ou vegetal. O Kefir pode ser consumido após a fermentação de forma pura, com adição de algum adoçante, polpas de fruta ou geleias (Oliveira, 2016).

Assim o presente trabalho analisou 35 trabalhos científicos sobre o desenvolvimento de novos produtos à base de Kefir (Tabela 1).

Tabela 1. Levantamento dos artigos brasileiros encontrados nos anos de 2006 a 2021 na literatura sobre o Kefir.

\begin{tabular}{|c|c|c|c|c|}
\hline $\begin{array}{c}\text { Subdivisões dos } \\
\text { produtos }\end{array}$ & Autores & Produtos à base de Kefir & Região & $\begin{array}{c}\text { Ano de } \\
\text { publicação }\end{array}$ \\
\hline \multicolumn{5}{|l|}{ Diversos } \\
\hline & Cardoso et al. & $\begin{array}{l}\text { Base de cerveja estilo sour empregando Kefir e } \\
\text { Kombucha }\end{array}$ & Bahia (Ilhéus) & 2021 \\
\hline & Oliveira et al. & $\begin{array}{l}\text { Salame elaborado com a utilização de Kefir como } \\
\text { cultura iniciadora }\end{array}$ & $\begin{array}{l}\text { Minas Gerais } \\
\text { (Rio Pomba) }\end{array}$ & 2021 \\
\hline & Ramos et al. & Mousse com adição de Kefir & Rio de Janeiro & 2020 \\
\hline
\end{tabular}


(Rio de Janeiro)

Patarro et al. Smoothies do leite de diferentes espécies fermentado por Kefir, saborizados com banana e maçã

Pinheiro et al. $\quad$ Frozen de Kefir com polpa de fruta

Granado et al.

Dornelles \&

Rodrigues

Moura et al.
Patê de Frango adicionado de probiótico de Kefir e enriquecido com farinha de cenoura

(São Miguel do

Fermentação de Caldo de cana utilizando grãos de Kefir

Antepasto de Kefir enriquecido com Lactobacillus acidophilus La-5 e coprodutos agroindustriais

Minas Gerais

(Rio Pomba)

Santa Catarina

Oeste)

Ceará

(Fortaleza)

Minas Gerais

Goiás

2020

(Rio Pomba)

\begin{tabular}{|c|c|c|c|c|}
\hline Antepasto & & & & \\
\hline & Campolina & Antepasto funcional utilizando Kefir e semente de chia & $\begin{array}{l}\text { Minas Gerais } \\
\text { (Florestal) }\end{array}$ & 2017 \\
\hline \multicolumn{5}{|l|}{ Queijos } \\
\hline & Alves et al & $\begin{array}{l}\text { Queijo minas frescal adicionado de leite fermentado de } \\
\text { Kefir }\end{array}$ & $\begin{array}{l}\text { Minas Gerais } \\
\text { (Rio Pomba) }\end{array}$ & 2021 \\
\hline & & & Rio Grande do & \\
\hline & Silva \& Weschenfeld & Queijo de Kefir com e sem condimentos & Sul (Novo & 2020 \\
\hline & & & Hamburgo) & \\
\hline & Oliveira et al. & $\begin{array}{l}\text { Queijos frescais fermentados com Kefir de leite e Kefir } \\
\text { de água }\end{array}$ & $\begin{array}{c}\text { Goiás (Rio } \\
\text { Verde) }\end{array}$ & 2020 \\
\hline & Santos et al. & $\begin{array}{l}\text { Petit suisse prebiótico de leite de Búfala fermentado } \\
\text { com Kefir }\end{array}$ & $\begin{array}{c}\text { Paraíba } \\
\text { (Campina } \\
\text { Grande) }\end{array}$ & 2018 \\
\hline & Matanna et al. & Queijo cremoso com Kefir & $\begin{array}{c}\text { Paraná } \\
\text { (Curitiba) }\end{array}$ & 2017 \\
\hline & Silva et al. & Sorvete de Kefir saborizado com geleia de maracujá & $\begin{array}{l}\text { Goiás (Rio } \\
\text { Verde) }\end{array}$ & $2020^{\mathrm{a}}$ \\
\hline
\end{tabular}

\section{Sorvetes}

Sorvete a base de isolado proteico de soro fermentado com Kefir
Paraná
(Londrina)

2020 
Research, Society and Development, v. 10, n. 7, e19010716491, 2021

(CC BY 4.0) | ISSN 2525-3409 | DOI: http://dx.doi.org/10.33448/rsd-v10i7.16491

$\begin{array}{clrl}\text { Ferreira et al. } & \begin{array}{l}\text { Sorvetes de diferentes leites fermentados por Kefir, } \\ \text { jabuticaba e mel de abelha silvestre }\end{array} & \begin{array}{c}\text { Paraná } \\ \text { (Curitiba) }\end{array} & 2020 \\ \text { Santos \& Mattanna } & \begin{array}{l}\text { Sorvete de cupuaçu elaborado com leite fermentado por } \\ \text { Kefir }\end{array} & \begin{array}{c}\text { Paraná } \\ \text { (Curitiba) }\end{array} & 2018 \\ \text { Parreiras et al. } & \text { Sorvete de Kefir com polpa de manga } & \begin{array}{c}\text { Bahia } \\ \text { (Salvador) }\end{array} & 2018 \\ \text { Silva et al. } & \text { Kefir em polpa de açaí } & \text { Pará (Belém) } & 2020 b\end{array}$

Fermentado de Kefir saborizado

\begin{tabular}{|c|c|}
\hline Alves & $\begin{array}{l}\text { Bebida fermentada de Kefir de água em extrato vegetal } \\
\text { Hidrossolúvel de coco com adição de inulina. }\end{array}$ \\
\hline Gomes et al. & bebida à base de Kefir saborizada com pequi \\
\hline Araújo et al. & Kefir em leite de coco babaçu \\
\hline D'Angelis et al. & $\begin{array}{l}\text { leites fermentados de Kefir saborizados com frutas } \\
\text { verdes e adicionados de inulina }\end{array}$ \\
\hline Sales et al. & Kefir com adição de polpa de açaí \\
\hline Gonçalves & $\begin{array}{l}\text { Iogurte grego com leite de cabra, fermentado por Kefir } \\
\text { e adicionado de fruta }\end{array}$ \\
\hline Silva & $\begin{array}{l}\text { Iogurte a base do leite fermentado de Kefir saborizado } \\
\text { com geleia de banana da prata }\end{array}$ \\
\hline Costa et al. & $\begin{array}{l}\text { Bebida látea fermentada com Kefir enriquecida com } \\
\text { amora-preta }\end{array}$ \\
\hline
\end{tabular}

Paraná

(Laranjeiras do 2020

Sul)

Piauí

(Teresina)

Piauí (Teresina) 2020

Minas Gerais

(São João del-

2020

Rei)

Ceará

(Fortaleza)

Paraíba

(Bananeiras)

Bahia

(Governador

2019

Mangabeira)

Rio Grande do

Sul (Santana do

Livramento)

Contim et al. Kefir com polpa de graviola

Amazonas

(Manaus)

Tavares et al.

Bebida fermentada Kefir de quinoa saborizada com cacau em pó

Bahia

(Salvador)

Santos

Kefir sem lactose adicionado de polpa de beterraba

Piauí (Teresina)

Sales.

Kefir elaborado com adição de polpa de açaí

Ceará

(Fortaleza) 


$\begin{array}{clcc}\text { Souza et al. } & \text { Kefir de café } & \begin{array}{c}\text { Espirito Santo } \\ \text { (Vitória) }\end{array} & 2016 \\ \text { Pietta \& Palezi } & \begin{array}{l}\text { Iogurte sabor mirtilo à base de Kefir com baixo teor de } \\ \text { lactose }\end{array} & \begin{array}{c}\text { Ceará } \\ \text { (Fortaleza) }\end{array} & 2015 \\ \text { Cabral } & \text { Kefir sabor chocolate } & \text { Rio de Janeiro } & 2014 \\ & & \text { (Niterói) }\end{array}$

Fonte: Autoria própria (2021).

Cardoso e colaboradores (2021) desenvolveu formulações para cerveja estilo sour, uma amostra foi acrescentado com Kefir e o outro com Kombucha. A cerveja a base de Kefir apresentou boa aceitabilidade e intenção de compra e foi destacado pela suavidade, sabor frutado, corpo da cerveja, amargor e acidez equilibrada (Tabela 1). Oliveira et al. (2021), desenvolveu um salame que utilizou o Kefir como cultura inicializadora. Observou-se que o desenvolvimento do salame com o Kefir possibilitou o aumento da acidez, o que impacta positivamente na segurança do produto. Além disso, o produto apresentou boa aceitação sensorial.

Ramos et al. (2020), elaborou um mousse de chocolate com Kefir que apresentou boa aceitação sensorial, entretanto, os atributos aroma e consistência foram avaliados por alguns provadores com notas negativas, o que o autor sugere que a formulação precisa passar por algumas modificações. Já Patarro e colaboradores (2020), formulou um Smoothies do leite de diferentes espécies fermentado com Kefir, como saborizados com banana e maçã, que consistia no leite bovino, caprino e ovino. Ao analisar as características sensoriais, o smoothie de leite de cabra foi o que apresentou melhor aceitação em relação a cor e aspecto brilhoso, devido a sua coloração mais opaca, no entanto em relação ao aroma e textura, o smoothie de leite de vaca foi o que apresentou maior aceitação. Em relação a intenção de compra do produto, o smoothie de leite de cabra se destacou, apresentando melhor aceitação.

Pinheiro et al. (2020), produziu um Frozen de Kefir com polpa de fruta, que infelizmente apresentaram uma concentração de coliformes termotolerantes superior ao limite estipulado pela legislação, assim sendo impossibilitado de realizar a análise sensorial do produto.

Granado et al (2016), desenvolveu uma formulação de patê de frango adicionado de probiótico de Kefir e enriquecido com farinha de cenoura. A formulação apresentou um alto índice de aceitabilidade, o que torna o produto um atrativo para quem busca alimentos diferenciados. Dornelles \& Rodrigues (2006), elaborou uma fermentação de Caldo de cana utilizando grãos de Kefir, a bebida apresentou menor teor alcoólico e consequentemente maior teor residual de açúcar quando comparado com uma mesma formulação fermentado com a Saccharomyces cereviseae8.

Moura et al (2020), produziu um antepasto de Kefir enriquecido com Lactobacillus acidophilus La-5 e coprodutos agroindustriais. As formulações de antepasto apresentaram boa aceitação, se mostrando eficiente devido ao baixo custo e alto valor nutricional do produto. Entretanto, a formulação padrão, sem adição dos coprodutos agroindustriais apresentaram maior aceitação entre os provadores. Campolina (2017) também desenvolveram uma formulação de antepasto funcional utilizando Kefir e semente de chia, observou-se que quanto maior a concentração de chia, maior os teores de proteína, lipídeos, fibras e menor o teor de umidade.

Alves et al. (2021), formulou um queijo minas frescal adicionado de leite fermentado de Kefir onde variou-se as concentrações dos grãos de Kefir, os produtos foram avaliados sensorialmente e apresentaram boa aceitação, entretanto, ao analisar a intenção de compra observou-se que $60 \%$ dos provadores optariam em comprar o queijo minas frescal com a menor concentração de Kefir, o que pode indicar uma preferência pelo queijo produzido de forma tradicional. Silva \& Weschenfeld 
(2020) também produziu duas formulações de queijo de Kefir, com e sem condimentos, onde ambos os queijos apresentaram características sensoriais boas, não apresentando diferenças nos aspectos avaliados.

Oliveira e colaboradores (2020), elaboraram queijos frescais fermentados com Kefir de leite e Kefir de água, onde puderam notar que não houve diferença sensorial entre as concentrações de Kefir, onde foi optado por trabalhar somente com a menor concentração (1\%) para uma maior segurança nos aspectos físico-químicos. O produto apresentou alta aceitabilidade tanto no queijo com Kefir de água quanto de leite.

Santos \& Mattanna (2018), desenvolveu um petit suisse prebiótico de leite de Búfala fermentado com Kefir variando a concentração de inulina, onde observou-se que a inulina afeta a coloração e a textura do produto. Por isso, a formulação que apresentou melhore aceitação sensorial foi que continha a menor concentração de inulina (5\%).

Matanna et al (2017) formulou um queijo cremoso com Kefir que apresentou baixo teor lipídico, sendo um fator importante para quem precisa de uma dieta que necessita de baixo consumo de gordura. O produto apresentou boa aceitação sensorial em todos os aspectos analisados.

Silva et al (2020a), produziu um sorvete de Kefir saborizado com geleia de maracujá, onde o fermentado de Kefir foi utilizado somente como substituídos parcial do leite. O produto apresentou resultados satisfatório, sendo agradável visualmente e não apresentou sabor residual.

Bae et al (2020) elaborou um sorvete a base de isolado proteico de soro fermentado com Kefir onde produziu três formulações com base na formulação padrão de sorvete, onde em cada uma delas adicionou-se um ingrediente alimentar diferente, inulina, polidextrose e maltodextrina na proporção de 5 e $6 \%$. As três formulações apresentam alto teor proteico que pode estar associado as formulações terem sido produzidas com soro de leite, fazendo com que o sorvete possa ter alegação funcional. Além disso, as formulações apresentaram teores lipídicos inferiores ao sorvete padrão, uma vez que a gordura foi substituída por inulina, polidextrose e maltodextrina que ajudam a conferir textura e cremosidade, esse baixo teor pode conferir ao produto ser considerado diet. Além disso, os sorvetes foram bem aceitos pelos provadores, o que indica que a inulina, polidextrose e maltodextrina podem ser ótimos substitutos para a gordura e açucares, além de melhorar as características nutricionais do produto.

Ferreira et al (2020) desenvolveu sorvetes de diferentes leites fermentados por Kefir, jabuticaba e mel de abelha silvestre, onde foi formulado com leite bovino e caprino. As amostras de sorvete foram avaliadas sensorialmente por provadores que avaliaram, em todos os aspectos, o sorvete fermentado bovino com as maiores notas, isso pode se justificar devido ao pouco consumo do leite caprino no país, uma vez que apresentou menor aceitabilidade devido as suas características próprias.

Santos \& Mattanna (2018) formulou um sorvete de cupuaçu elaborado com leite fermentado por Kefir, onde apresentou boa aceitação em todos os aspectos analisados sensorialmente. Além de apresentar uma alta intenção de compra.

Parreiras et al (2018) produziu sorvete de Kefir com polpa de manga. Os autores observaram que o produto apresentou boa aceitação sensorial independente da concentração de Kefir e ainda que o sorvete com 5\% de Kefir apresentou um paladar com menor acidez.

Silva et al (2020b) desenvolveu uma formulação de Kefir em polpa de açaí. A adição de polpa de açaí ao Kefir se mostrou bastante relevante uma vez que favoreceu o crescimento microbiano, saborizou o Kefir o que pode ser um fator determinante quanto a aceitabilidade do produto, além de ser rico em fibras. Sales et al (2020) também produziu uma formulação de Kefir com adição de polpa de açaí, foram elaboradas 8 formulações em que se distinguiam de acordo com a concentração de polpa de Kefir e o tempo de fermentação. Observou-se que a relação tempo de fermentação e porcentagem de polpa de açaí foram critérios importante na avaliação sensorial. Todas as formulações apresentaram boa aceitabilidade, porém a formulação de 36 horas de fermentação e 20\% de polpa apresentou a melhor aceitação. Sales (2017) formulou um Kefir elaborado com adição de polpa de açaí em diferentes concentrações, as formulações apresentaram boa aceitação sensorial em 
todos os aspectos analisados, entretanto o produto padrão apresentou melhor aceitação. Além disso, em relação ao tempo de fermentação do Kefir, o que apresentou melhor aceitação foi o de $24 \mathrm{~h}$ por apresentar menor acidez.

Alves (2020) elaborou uma bebida fermentada de Kefir de água em extrato vegetal Hidrossolúvel de coco com adição de inulina, onde variou as concentrações de açúcar de coco, inulina e goma xantana. Ao se analisar aspectos físico-químicos das bebidas, foi possível perceber que a fermentação de 24 horas foi a mais adequada em relação ao pH. Além disso, o Extrato vegetal Hidrossolúvel de coco na bebida fermentada de Kefir apresentou baixo teor calórico e proteico, alto valor lipídico. Sendo assim, a bebida se torna uma ótima opção para pessoas veganas.

Gomes e colaboradores (2020) produziram uma bebida à base de Kefir saborizada com pequi. Os autores observaram que bebida saborizada de pequi obteve todas as suas características físico-químicas como esperadas de acordo com a legislação.

Araújo et al (2020) formulou um fermentado de Kefir em leite de coco babaçu, onde foram produzidas em quatro formulações, três delas continham a mistura de leite UHT e leite de coco de babaçu enquanto uma foi elaborada somente com leite de coco de babaçu. As três formulações que apresentavam misturas obtiveram duas fases, onde os leites não se misturaram e apresentaram colorações distintas, o leite UHT ficou branquinho e o leite de coco babaçu marrom escuto e extremamente oleosa. Foi somente na formulação 100\% de leite de coco babaçu que o odor ficou característico e agradável, manifestou-se também uma coloração marrom clara. Foi comparado o iogurte $100 \%$ de leite de coco babaçu e $100 \%$ leite UHT sendo observado que o iogurte do leite UHT apresenta coloração branca, textura macia, encorpada e de odor característico enquanto do iogurte de leite de babaçu apresentou coloração marrom clara, textura granulosa devido a parte fibrosa da trituração, mais oleosa e odor característico de coco babaçu. O iogurte desenvolvido a partir do leite fermentado apresentou alto potencial probiótico, uma vez que absorveu as fibras, ácido láurico e óleo vegetal presentes no coco babaçu.

D'Angelis et al (2020) desenvolveu um leite fermentado de Kefir saborizado com frutas verdes e adicionados de inulina com formulações contendo grãos de Kefir e starter. Foi possível observar que a adição de inulina não influenciou no processo de fermentação, não alterando a acidez e nem o pH das formulações. As bebidas formuladas com os grãos de Kefir apresentaram maior acidez e menor pH que os da formulação com starter, isso pode ser justificado devido a microbiota mais diversa e complexa presente nos grãos. Entretanto, apenas as formulações com starter liofilizada que apresentaram valores de acidez de acordo com a legislação.

Gonçalves (2019) produziram um iogurte grego com leite de cabra, fermentado por Kefir e adicionado de fruta e apresentou boas analises microbiológicas, o que indica que o produto se encontra dentro da legislação.

Silva (2019) formulou um iogurte a base do leite fermentado de Kefir saborizado com geleia de banana da prata, o produto apresentou boa aceitação sensorial nos aspectos analisados o que indica que o produto tem grande potencial para ser inserido no mercado alimentício.

Costa et al (2018) desenvolveram uma bebida látea fermentada com Kefir enriquecida com amora-preta, ao analisar suas características funcionais foi possível notar que a amostra com adição de geleia de amora-preta elevou a atividade antioxidante devido à presença em uma quantidade quase 3 vezes maior de compostos fenólicos que a formulação tradicional.

Contim et al. (2018) elaborou um Kefir com polpa de graviola, onde observou que a amostra apresentava maior teor alcoólico na bebida, isso pode ser justificado devido ao aumento da concentração de açúcar da bebida. O produto apresentou altos valores nos atributos avaliados na análise sensorial.

Tavares et al. (2018) desenvolveu uma bebida fermentada Kefir de quinoa saborizada com cacau em pó, o produto passou por um teste de extração DNA e PCR-DGGE para analisar a constituição microbiológica presente na bebida. Diante de todos os microrganismos encontrados presentes na bebida, ela pode ser considerada uma bebida com potencial probiótica, além de não ter apresentado a presença de nenhum microrganismo indesejável, tornando a bebida segura ao consumo. Em relação ao teor de cinzas, proteico e lipídicos houve um aumento bem significativo na formulação fermentada o que pode estar associado 
a adição de cacau em pó, uma vez que apresenta um teor proteico e lipídico considerável em sua composição. Com relação aos tributos sensoriais analisados, a bebida fermentada de quinoa e cacau em pó apresentou boa aceitação.

Santos (2017) produziu um Kefir sem lactose adicionado de polpa de beterraba. O produto apresentou baixa intenção de compra e nos aspectos de textura, sabor e odor foi avaliado negativamente.

Souza et al (2016) elaborou um Kefir de Café, que apresentou boa aceitabilidade pelos provadores tanto nas características sensoriais quanto na intenção de compra.

Pietta \& Palezi (2015) desenvolveu um iogurte sabor mirtilo à base de Kefir com baixo teor de lactose. Com relação aos aspectos físico-químicos, todos os aspectos se encontravam dentro da faixa de aceitação pela legislação. A formulação foi avaliada quanto a sua aceitação sensorial e apresentou altos valores de aceitação sensorial, indicando que o produto pode ser bem aceito comercialmente.

Cabral (2014) formulou um Kefir de chocolate, onde foi desenvolvido duas formulações alterando somente a concentração de grânulos de Kefir entre 5 e 10\% e saborizado com cacau em pó. Em relação ao aspectos físico-químicos das formulações, todos apresentaram teores esperados de acordo com a literatura.

Conforme o levantamento dos artigos, foi possível verificar que houve um aumento de artigos publicados com desenvolvimento de novos produtos à base de Kefir no ano de 2020 (Figura 1).

Figura. 1. Levantamento bibliográfico de artigos com desenvolvimento de novos produtos à base de Kefir no período de 2006 a 2021 .

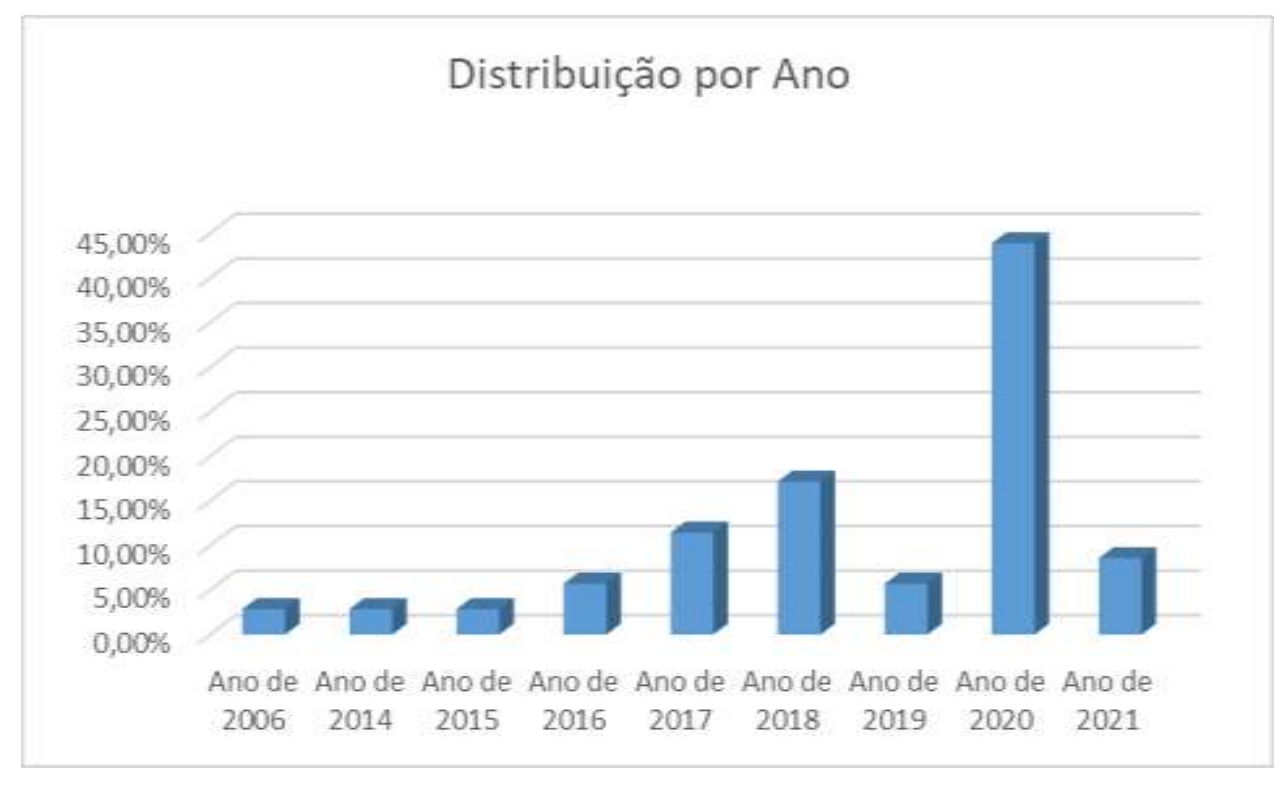

Fonte: Autoria própria (2021).

Foi possível observar que com o passar dos anos houve um crescimento com relação ao estudo do desenvolvimento de novos produtos à base de Kefir. É possível observar que no ano de 2019 houve um decréscimo dos estudos relacionados ao tema. De acordo com Román et al. (2019), o ano de 2019 apresentou o menor orçamento dos últimos anos para o setor de Ciência, Tecnologia e Inovação no Brasil, o orçamento foi de cerca de um terço do orçamento em 2010. Isso pode ter influenciado no decréscimo de estudos técnico científico sobre o desenvolvimento de novos produtos à base de Kefir.

Com relação ao baixo número de pesquisas técnico científicas no ano de 2021, isso pode estar associado a não conclusão do primeiro semestre do ano, o que indica a possibilidade de que muitos artigos ainda não tenham sido publicados. 
Esse crescimento analisado na Figura 1 pode ser justificado com o aumento da busca por uma alimentação mais saudável, devido ao aumento de doenças crônicas não transmissíveis (Dias et al., 2020). Desta forma, o mercado alimentício precisa se inovar para atender a demanda pela crescente busca por alimentos mais nutritivos ou com propostas diferentes e específicas. Essa nova tendência reforçam o desenvolvimento de alimentos funcionais (Silva, 2019).

Além disso, o aumento exponencial de estudos relacionados ao desenvolvimento de novos produtos à base de Kefir no ano de 2020, pode estar atrelado também à pandemia de COVID 19, que possibilitou que muitos pesquisadores conseguissem se dedicar mais as pesquisas.

Se analisarmos a Tabela 1, observamos que os artigos analisados podem ser subdivididos em 5 classes de desenvolvimento de novos produtos à base de Kefir, sendo elas: queijos, fermentados de Kefir saborizados/ iogurtes saborizados, sorvetes, antepastos e produtos diversos. A subclasse que representa os produtos diversos foi definida como um produto a base de Kefir que só foi encontrada em um único artigo. Com base nessa subdivisão foi desenvolvido o Figura 2 que representa essa distribuição.

Figura 2. Subdivisões de produtos à base de Kefir, levantados dos artigos no período de 2006 a 2021.

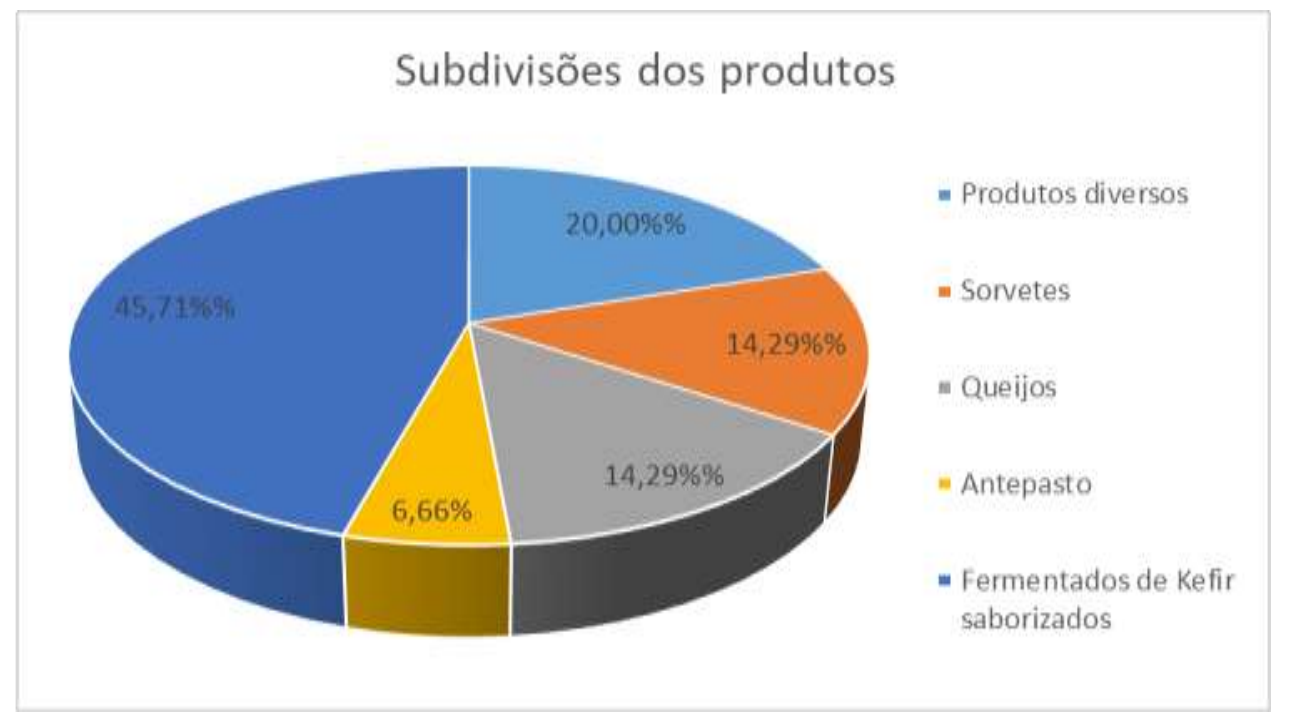

Fonte: Autoria própria (2021).

Com base na Figura 2, observou-se que a maioria dos artigos encontrados na literatura sobre o desenvolvimento de novos produtos à base de Kefir, se deu através do fermentado de Kefir, conhecido como iogurte de Kefir, saborizado. Essa grande parcela representa cerca de $45,71 \%$, o que indica que estudiosos buscam a melhor aceitação do fermentado de Kefir

Isso porque o fermentado de Kefir apresenta um sabor marcante característico, que é mais forte ao paladar que os fermentados tradicionais, o que acarreta a diminuição da aceitação sensorial. Dessa forma, uma alternativa é a adição de frutas (Silva, 2019).

Dos artigos analisados (Tabela 1) 54,29\% representam produtos diversos, sorvetes, queijos e antepastos, que indicam a busca por novas formulações a base Kefir, uma vez que ele entra como substituinte de alguns componentes na formulação.

Foi possível observar que o estado de Minas Gerais publicou 17,14\% dos trabalhos com alimentos à base de Kefir, seguido do Paraná com 14,28\% das publicações e em terceiro lugar o Estado da Bahia e o Ceará com 11,43\% (Figura 3).

Os artigos encontrados não contemplam todos os estados brasileiros, representando somente 50\% dos estados. Segundo Barros (2020), a diferença na distribuição regional dos recursos científicos e tecnológicos está associado a distribuição de incentivos financeiros mais expressivos em determinados estados. 
Minas Gerais apresentou publicações com $100 \%$ dos artigos relacionados a antepastos, $20 \%$ a queijos e $28,57 \%$ de produtos diversos e 4,76\% de fermentados a base de Kefir

Os estados que apresentaram menor porcentagem em desenvolvimento de novos produtos, se encontram com $2,85 \%$ são eles: o Amazonas, Espírito Santo, Pará e Santa Catarina. Destes 4 estados, 3 deles produziram apenas artigos da classe de fermentados de Kefir saborizados, onde apenas o estado de Santa Catarina produziu um artigo da classe de produtos diversos a base de Kefir.

Figura 3. Levantamento das publicações de artigos de produtos à base de Kefir por Estados no Brasil.

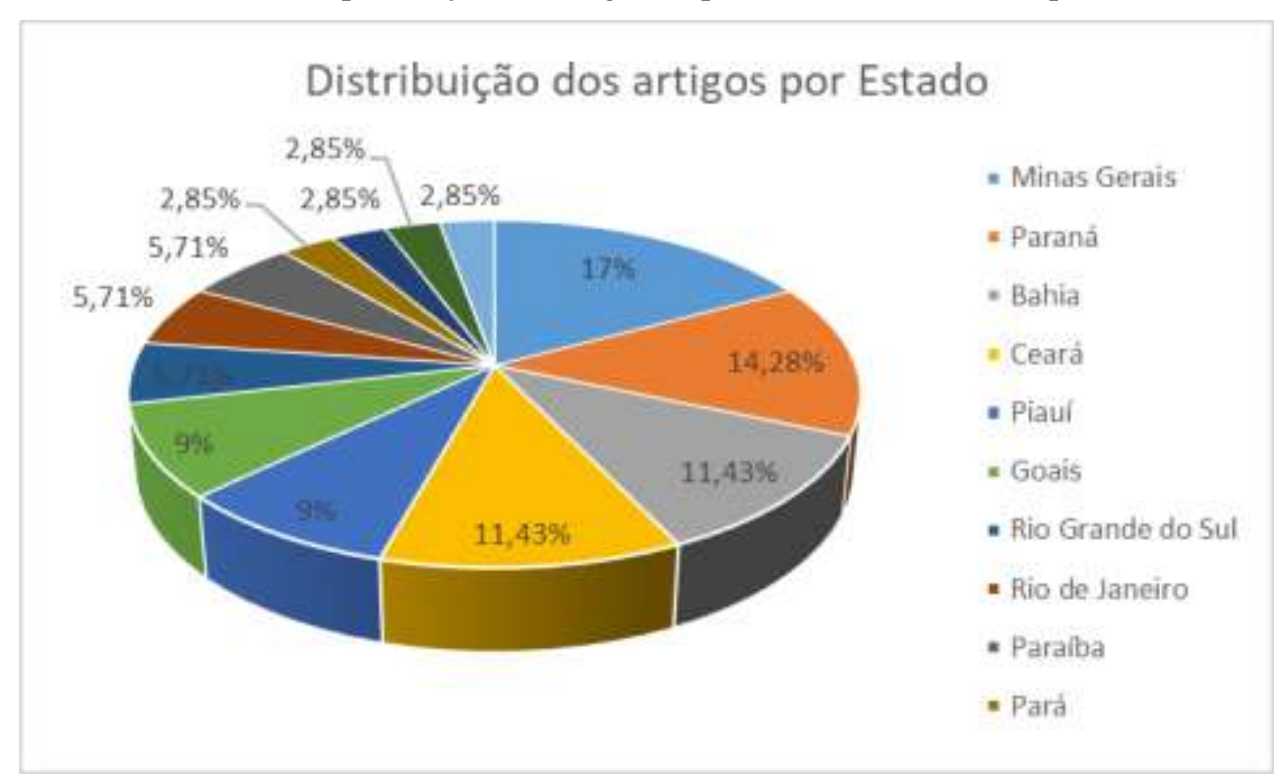

Fonte: Autoria própria (2021).

Ao analisar a Tabela 1, é possível observar que um número muito expressivo de artigos, que buscaram desenvolver novos produtos à base de Kefir, não passaram por testes de análise sensorial. O que indica que esses estudos precisam ser mais aprofundados, para melhor se determinar se o produto será aceito no mercado alimentício.

Dos produtos em que foram avaliados sensorialmente, 97,14\% deles apresentaram boa aceitação sensorial, o que se torna um grande incentivador ao desenvolvimento de novas formulações a base de Kefir.

\section{Considerações Finais}

Com o presente estudo foi possível analisar o crescimento do número de pesquisas técnico-científicas relacionados ao Kefir, uma vez que se aumentou o interesse da população por uma alimentação mais saudável.

Devido aos inúmeros benefícios associados ao consumo regular de Kefir, é imprescindível que haja um incentivo as pesquisas relacionadas ao tema, em busca de aumentar o acesso da população a esse probiótico.

Sugerimos como futuros trabalhos o desenvolvimento de um mapeamento da composição microbiológica dos grânulos de Kefir de diferentes origens afim de comparação.

\section{Agradecimentos}

Ao CNPq, Capes e à UFTM pelo incentivo e apoio à pesquisa. 


\section{Referências}

Alves, L. A. B., de Oliveira Martins, A. D., do Nascimento, W. C. A., Martins, J. M., Souza, V. R. O., Chaves, K. F., \& da Silva, R. R. (2021). Queijo minas frescal adicionado de leite fermentado de kefir: análises microbiológicas e sensoriais. Alimentos: Ciência, Tecnologia e Meio Ambiente, 1(12), 13-28. https://revistascientificas.ifrj.edu.br/revista/index.php/alimentos/article/view/1762/1078.

Alves, V. (2020). Desenvolvimento de bebida fermentada com kefir de água em extrato vegetal hidrossolúvel de coco (cocos nucifera 1.) com adição de inulina. https://rd.uffs.edu.br/bitstream/prefix/3919/1/ALVES.pdf.

Arabbi, P. R. (2001). Alimentos funcionais-aspectos gerais. Nutrire Rev. Soc. Bras. Aliment. Nutr, 87-102. http://sban.cloudpainel.com.br/files/revistas_publicacoes/18.pdf.

Araújo, J.C, Ribeiro, N. M., Bezerra, K. C. B., \& Landim, L. A. D. S. R. (2020). Desenvolvimento de kefir em leite de coco babaçu. Research, Society and Development, 9(11), e3559119891-e3559119891. https://www.rsdjournal.org/index.php/rsd/article/view/9891/8859.

Bae, F. A. H., Saito, P. T., Garcia, S., Sakanaka, L. S., \& Ueno, C. T. (2020). Desenvolvimento, caracterização fisíco-química e aceitação sensorial de sorvete a base de isolado proteico de soro de leite. http://schenautomacao.com.br/ssa7/envio/files/trabalho3_364.pdf.

Barros, F. A. F. (2000). Os desequilíbrios regionais da produção técnico-científica. São Paulo em perspectiva, 14(3), 12-19. https://www.scielo.br/scielo.php?pid=S0102-88392000000300004\&script=sci_arttext.

BRASIL. (2007). Ministério da Agricultura, Pecuária e Abastecimento. Instrução Normativa no 46 de 23 de outubro de 2007. Regulamento Técnico de Identidade e Qualidade de Leites Fermentados. Diário Oficial da República Federativa do Brasil, Brasília, DF, 24 de out. 2007.

Cabral, N. S. M. (2014). Kefir sabor chocolate: caracterização microbiológica e físico-química. https://app.uff.br/riuff/handle/1/1049.

Campolina, G. A., da Silva Faria, M. A., Carvalho, N. B., \& Villanoeva, C. N. B. (2017). Elaboração e caracterização físico-química de antepastos funcionais utilizando kefir e semente de chia. Caderno de Ciências Agrárias, 9(3, supl. 1), 24-31. https://periodicos.ufmg.br/index.php/ccaufmg/article/view/2998/1821.

Cardoso, M. P. S., Macedo, K. M., de Souza, V. S. N., Maldonado, R. R., Figueiredo, A. F. R., \& Aguiar-Oliveira, E. (2021). Desenvolvimento de duas formulações base de cerveja estilo sour empregando kefir e kombucha na fermentação. Brazilian Journal of Development, 7(1), 5616-5628. https://www.brazilianjournals.com/index.php/BRJD/article/view/23212/18643.

Contim, L. S. R., Oliveira, I. M. A., \& Cardoso Neto, J. (2018). Avaliação microbiológica, físico-química e aceitação sensorial do kefir com polpa de graviola. Revista do Instituto de Laticínios Cândido Tostes, 73(1), 1-9.

Coppola, M. D. M., \& Gil-Turnes, C. (2004). Probióticos e resposta imune. Ciência rural, 34(4), 1297-1303. https://www.scielo.br/scielo.php?pid=s0103$84782004000400056 \&$ script=sci_arttext.

Costa, E., dos Santos, J. B. D. R., Pereira, M. C., \& Mello, F. F. (2018). Aspectos físico-químicos e funcionais de bebida látea fermentada com kefir enriquecida com amora-preta (Rubus, SP.). Anais do Salão Internacional de Ensino, Pesquisa e Extensão, 10(2). https://guri.unipampa.edu.br/uploads/evt/arq_trabalhos/18077/seer_18077.pdf.

Costa, M. P., Balthazar, C. F., Moreira, R. D. B. P., da Cruz, A. G., \& Conte Júnior, C. (2013). Leite fermentado: potencial alimento funcional. Enciclopédia Biosfera, 9, $1387-1408$. https://www.researchgate.net/profile/Carlos-ConteJunior/publication/266395821_Leite_fermentado_potencial_alimento_funcional_Fermented_milk_potential_functional_food/links/5431d2630cf27e39fa9f962 b/Leite-fermentado-potencial-alimento-funcional-Fermented-milk-potential-functional-food.pdf.

Cunha, T. M., de Castro, F. P., Barreto, P. L. M., Benedet, H. D., \& Prudêncio, E. S. (2008). Avaliação físico-química, microbiológica e reológica de bebida láctea e leite fermentado adicionados de probióticos. Semina: Ciências Agrárias, 29(1), 103-116 https://www.redalyc.org/pdf/4457/445744087010.pdf.

Dias, W. C., de Oliveira Martins, A. D., \& Moreira Júnior, S. (2020). KEFIR: Características e benefícios. Alimentos: Ciência, Tecnologia e Meio Ambiente, 1(7), 22-42. https://revistascientificas.ifrj.edu.br/revista/index.php/alimentos/article/view/1633/931.

D’Angelis, D. F., Gonçalves, A. C. A., da Veiga Correia, V. T., Kobori, C. N., \& Ubaldo, J. C. S. R. (2020). Elaboração, caracterização físico-química e sensorial de leites fermentados de kefir saborizados com frutas verdes e adicionados de inulina. Research, Society and Development, 9(9), e246997179e246997179.

Dornelles, A. S., \& Rodrigues, S. (2006). Fermentação alcoólica de caldo de cana utilizando grãos de kefir. Revista Ciência Agronômica, 37(3), 386-390.

Ferreira, J. V., da Silva Schirmann, G., de los Santos, M. L. P., Zago, A. C., de Souza Bortolini, V. M., Rockenbach, R., \& Bragança, G. C. M. (2020). Parâmetros físico-químicos e aceitabilidade de sorvetes desenvolvidos a partir de diferentes leites fermentados por kefir, jabuticaba (Myrciaria cauliflora (Mart.) O. Berg) e mel de abelha silvestre. Brazilian Journal of Development, 6(11), 85434-85451. https://www.brazilianjournals.com/index.php/BRJD/article/view/19415/15588.

Gomes, F.O., da Silva, M. D. C. M., de Sousa, P. B., Freitas, T. K. T., Silva, D. J. S., \& Araújo, R. S. D. R. M. (2020). Avaliação físico-química de uma bebida à base de kefir saborizada com pequi. Brazilian Journal of Development, 6(3), 10755-10762. https://www.brazilianjournals.com/index.php/BRJD/article/view/7427/6480.

Gonçalves, I. F., Martins, E. M. F., Silva, V. R. O., \& de Oliveira Martins, A. D. (2018). Efeito de yacon na aceitação sensorial de kefir e viabilidade de bactérias láticas na bebida.

Gonçalves, L.S.C. (2019). Elaboração e análise microbiológica de iogurte grego com leite de cabra, fermentado por kefir e adicionado de fruta. Revista Craibeiras de Agroecologia, 4(2). https://www.seer.ufal.br/index.php/era/article/viewFile/9219/6623.

Granado, C., Beilke, L., \& Palezi, S. C. (2016). Elaboração de Um Patê de Frango Adicionado de Microrganismo Probiótico do Gênero Kefir e Enriquecido com Farinha de Cenoura. Unoesc \& Ciência-ACET, Joaçaba/SC, 7(1), 61-68. https://core.ac.uk/download/pdf/235124583.pdf. 
Moraes, F. P. (2006). Alimentos funcionais e nutracêuticos: definições, legislação e benefícios à saúde. Revista eletrônica de farmácia, 3(2). https://www.revistas.ufg.br/REF/article/view/2082/2024.

Moura, A. D. C. T., Martins, E. M. F., Silva, V. R. O., da Silva, R. R., da Cruz, W. F., \& de Oliveira Martins, A. D. (2020). Avaliação sensorial de antepasto de kefir enriquecido com Lactobacillus acidophilus La-5 e coprodutos agroindustriais. Alimentos: Ciência, Tecnologia e Meio Ambiente, 1(2), 84-96. https://revistascientificas.ifrj.edu.br/revista/index.php/alimentos/article/view/1371/760.

Oliveira, A. F. (2016). Estudo da viabilidade da produção de biofilmes de kefir e suas interações com extratos de açaí (Euterpe oleracea Martius) e de gérmen de soja (Glycine max (L.) Merrill) (Doctoral dissertation, Tese (Universidade Federal do Amapá). https://www2.unifap.br/ppgbio/files/2017/07/TESEDEFINITIVA-31-01-17.pdf.

Oliveira, F. C. S., Farias, L. C. B., do Carmo, R. M., de Oliveira, L. A., de Oliveira Santos, G., Silva, M. S., ... \& da Silva, M. A. P. (2020). Características físico-químicas e sensoriais de queijos frescais fermentados com kefir de leite e kefir de água. Research, Society and Development, 9(4), e153943015e153943015. https://www.rsdjournal.org/index.php/rsd/article/view/3015/2211.

Oliveira, G. L., do Nascimento, W. C. A., Júnior, A. A. B., de Oliveira Martins, A. D., Silva, V. R. O., \& de Carvalho, M. M. (2021). Salames elaborados com a utilização de kefir como cultura iniciadora: aceitação sensorial e mapa de preferência interno. Alimentos: Ciência, Tecnologia e Meio Ambiente, 2(1), 72-87. https://revistascientificas.ifrj.edu.br/revista/index.php/alimentos/article/view/1830/1099.

Parreiras, P. M., de Souza Dantas, M. I., Coelho, A. I. M., \& de Souza, E. C. G. (2018). Desenvolvimento de sorvete de kefir com polpa de manga: avaliação sensorial, físico-química e de bactérias ácido láticas. Semina: Ciências Biológicas e da Saúde, 40(1), 109-118. http://www.uel.br/revistas/uel/index.php/seminabio/article/view/34866/26019.

Pattaro, L., Gonçalves, J. A., Farias, L. C. B., Medeiros, J. S., Teixeira, P. C., da Cunha, J. V. T., ... \& da Silva, M. A. P. (2020). Análises físico-químicas e sensoriais de smoothies do leite de diferentes espécies fermentado por kefir, saborizados com banana e maçã. Research, Society and Development, 9(5), e112953145-e112953145. https://www.rsdjournal.org/index.php/rsd/article/view/3145/4949.

Pietta, G. M., \& Palezi, S. C. (2015). Desenvolvimento de um iogurte sabor mirtilo à base de kefir e com reduzido teor de lactose. Unoesc \& CiênciaACET, 6(2), 163-172. https://unoesc.emnuvens.com.br/acet/article/view/8000/5076.

Pinheiro, P. S., da Silva Gonçalves, P., de Oliveira Martins, A. D., Alves, L. A. B., da Silva, R. R., Nogueira, C. H., \& Dias, W. C. (2020). Viabilidade de bactéria lática em frozen adicionado de kefir. Alimentos: Ciência, Tecnologia e Meio Ambiente, 1(6), 1-10. https://revistascientificas.ifrj.edu.br/revista/index.php/alimentos/article/view/1616/1093.

Ramos, E. M., de Oliveira, O. M. A., \& dos Santos Vilar, J. (2020). Elaboração e avaliação sensorial de mousse com adição de kefir. Brazilian Journal of Health Review, 3(1), 63-77. https://www.brazilianjournals.com/index.php/BJHR/article/view/5879/5275.

RÓMAN, V. (2019, novembro). Cortes em série fragilizam a ciência na américa latina. El país.

Sales, L. (2017). Caracterização e estabilidade de leite fermentado kefir elaborado com adição de polpa de açaí. Embrapa Agroindústria TropicalTese/dissertação. https://www.alice.cnptia.embrapa.br/alice/bitstream/doc/1101905/1/DissertacaoLIVIA.pdf.

Sales, L.G.M et al. (2020). Caracterização e estabilidade de Kefir com adição de polpa de açaí. Research, Society and Development, [s. l.]. https://www.rsdjournal.org/index.php/rsd/article/view/5189/4824.

Santos, A. V. D. (2012). Desenvolvimento de produtos lácteos fermentados por grãos de kefir com teor de colesterol reduzido e saborizados com frutas tropicais. https://mestrados.unit.br/wp-content/uploads/2013/03/Dissert.-PEP-Alysson-Vieira-dos-Santos.pdf.

Santos, F. B., \& Mattanna, P. (2018). Desenvolvimento de sorvete de cupuaçu elaborado com leite fermentado por kefir. Revista eletrônica biociências, biotecnologia e saúde, 11(20), 58-64. https://revistas.utp.br/index.php/GR1/article/view/2246/1869.

Santos, J. K. S. (2017). Elaboração de kefir sem lactose adicionado de polpa de beterraba (Beta vulgaris esculenta). http://bia.ifpi.edu.br/jspui/bitstream/prefix/461/3/2017_tcc_jkssantos.pdf.

Santos, R. M. S., De Sousa, F. M., Alves, J. I. D. S., De Almeida, R. D., De Gusmão, R. P., \& Gusmão, T. A. S. (2018). Elaboração e caracterização física de petit suisse prebiótico de leite de búfala fermentado com kefir. Revista Brasileira de Agrotecnologia,8(3), 10-14. https://www.gvaa.com.br/revista/index.php/REBAGRO/article/view/6259/5246.

Silva, E. M. (2019). Aceitabilidade de iogurte a base do leite fermentado de kefir saborizado com geleia de banana da prata. http://131.0.244.66:8082/jspui/bitstream/123456789/1581/1/Elivelton\%20Melo\%20Silva.pdf.

Silva, I. Z., \& Weschenfelder, S. (2020). Caracterização físico-química e sensorial em queijo de kefir com e sem condimentos. Revista do Instituto de Laticínios Cândido Tostes, 75(2), 83-93.

Silva, J. C. D. M. (2019). Bebida à base de soja fermentada com Kefir suplementada com polpa de bocaiúva (Acrocomia aculeata) e inulina. https://repositorio.ifgoiano.edu.br/bitstream/prefix/711/1/Disserta\%c3\%a7\%c3\%a3o_Juliane\%20Cristina\%20de\%20Melo\%20Silva.pdf.

Silva, M. S., de Oliveira Silva, F. C., Medeiros, J. S., Egea, M. B., de Sousa, T. L., \& da Silva, M. A. P. (2020a). Sorvete de kefir saborizado com geléia de maracujá. Alimentos: Ciência, Tecnologia e Meio Ambiente, 1(6), 122-133.

Silva, M. V., Nascimento, E. C. D. S., do Nascimento FERREIRA, E. C., \& GALÚCIO, V. C. A. (2020b). Análise de crescimento do kefir em polpa de açaí. Revista Saber Científico, 9(2), 1-10. http://revista.saolucas.edu.br/index.php/resc/article/view/1297/pdf.

Souza, M. H., da Silva, I. S., da Conceição Barbosa, M., Belizário, R. M., de Souza Cabral, R. M., Ribeiro, D. F., \& Rodrigues, F. C. (2016). Desenvolvimento e avaliação sensorial de kefir de café. Anais do Seminário Científico do UNIFACIG, (2). http://pensaracademico.unifacig.edu.br/index.php/semiariocientifico/article/view/68/53. 
Research, Society and Development, v. 10, n. 7, e19010716491, 2021

(CC BY 4.0) | ISSN 2525-3409 | DOI: http://dx.doi.org/10.33448/rsd-v10i7.16491

Matanna, P., Camargo, W., de Azevedo, T. C. R., Moreira, R. A., dos Santos, R. C., Machado, K. R., ... \& Sperotto, L. (2017). Desenvolvimento de queijo cremoso com kefir: Análises sensoriais e físico-químicas. Revista Eletrônica Biociências, Biotecnologia e Saúde,9(18), 60-68. https://seer.utp.br/index.php/GR1/article/view/1494/1261.

Tavares, P. P. L. G., Silva, M. R., Santos, L. F. P., Nunes, I. L., \& Magalhães-Guedes, K. T. (2018). Produção de bebida fermentada kefir de quinoa (Chenopodium quinoa) saborizada com cacau (Theobroma cacao) em pó. Revista Brasileira de Ciências Agrárias (Agrária), 13(4), 5593. http://www.agraria.pro.br/ojs-2.4.6/index.php?journal=agraria\&page=article\&op=view\&path\%5B\%5D=agraria_v13i4a5593\&path\%5B $\% 5 \mathrm{D}=5114$.

Vidal, A. M., Dias, D. O., Martins, E. S. M., Oliveira, R. S., Nascimento, R. M. S., \& da Silva Correia, M. D. G. (2012). A ingestão de alimentos funcionais e sua contribuição para a diminuição da incidência de doenças. Caderno de Graduação-Ciências Biológicas e da Saúde-UNIT-SERGIPE, 1(1), 43-52. https://periodicos.set.edu.br/cadernobiologicas/article/view/284/112. 